\title{
EFEKTIVITAS PENDISTRIBUSIAN AIR BERSIH PDAM TIRTA DAROY KOTA BANDA ACEH \\ (Studi Kasus Cabang Syiah Kuala dan Teuku Nyak Arief)
}

\author{
Bunyamin $^{1}$, Mery Silviana ${ }^{2}$ \\ ${ }^{1}$ Program Studi Teknik Sipil, Fakultas Teknik, Universitas Iskandar Muda; \\ ${ }^{2}$ Program Studi Teknik Sipil, Fakultas Teknik, Universitas Almuslim; \\ e-mail: *1 bunyamin@unida-aceh.ac.id \\ *22merysilviana85@gmail.com
}

\begin{abstract}
ABSTRAK
Air adalah salah satu prasarana kota yang amat penting dan dimanfaatkan untuk kebutuhan dasar manusia. Pemanfaatannya tidak hanya terbatas untuk keperluan rumah tangga tetapi juga untuk fasilitas umum, sosial maupun ekonomi. Salah satu cara untuk memperoleh air bersih adalah dengan memanfaatkan pelayanan Perusahaan Daerah Air Minum (PDAM). PDAM merupakan suatu badan usaha yang mengolah dan melayani kebutuhan air minum masyarakat. Salah satu permasalahan yang telah dan akan timbul dalam pengelolaan air bersih adalah kemampuan PDAM sebagai penyedia air bersih pada umumnya masih terbatas baik jangkauan maupun mutu pelayanannya. Penelitian ini bertujuan untuk mengetahui tingkat efektifitas pendistribusian air bersih PDAM Tirta Daroy Kota Banda Aceh berdasarkan persepsi responden di daerah pelayanan cabang Syiah Kuala dan cabang Teuku Nyak Arief ditinjau dari segi kuantitas air, kontinuitas pengaliran, dan kualitas air serta jumlah kehilangan air. Metode yang digunakan adalah metode kuantitatif yaitu dengan penyebaran kuisioner terhadap responden. Hasil penelitian menunjukkan bahwa berdasarkan persepsi 392 responden, tingkat efektifitas air bersih PDAM Tirta Daroy Kota Banda Aceh sudah efektif dengan nilai rata-rata 3,71 \%, ditinjau dari kuantitas air sudah mampu memenuhi seluruh kebutuhan pelanggan dengan nilai rata-rata $3,71 \%$, kontinuitas pengaliran selama 24 jam sudah baik dengan tingkat nilai rata-rata 3,99\%, dan kualitas air bersih yang dikonsumsi baik dari segi kekeruhan, bau dan rasa juga sudah efektif dengan nilai rata-rata 3,42\% dari responden.
\end{abstract}

Kata kunci: Penelitian, air bersih, kuantitas air, kontinuitas air, kualitas air.

\section{Pendahuluan}

Kehidupan masyarakat kota yang serba kompleks memerlukan dukungan prasarana kota yang memadai baik secara kuantitatif maupun kualitatif agar seluruh aktifitas penduduk dapat berjalan dengan aman, tertib, lancar dan sehat. Prasarana utama kota meliputi jalan, air bersih, saluran air bersih, saluran air kotor, saluran air hujan (drainase) dan pembuangan sampah serta lingkungan yang sehat. Salah satu prasarana kota yang amat penting adalah air bersih sekaligus kebutuhan dasar manusia. Pemanfaatannya tidak hanya terbatas untuk keperluan rumah tangga tetapi juga untuk fasilitas-fasilitas umum Kebutuhan air bersih akan terus meningkat seiring dengan perkembangan pembangunan yang sejalan dengan pertambahan penduduk. Dengan adanya pertumbuhan penduduk, terjadi dinamika dalam masyarakat baik dalam segi kepadatan, sosial ekonomi, sehingga kebutuhan air bersih pun akan meningkat.

Air merupakan salah satu sumberdaya alam yang sangat penting bagi kehidupan manusia, baik untuk memenuhi kebutuhan hidup sehari-hari maupun untuk kepentingan lainnya seperti pertanian dan indutri. Oleh karena itu keberadaan air dalam masyarakat perlu dipelihara dan dilestarikan bagi kelangsungan kehidupan.

Suatu sistem penyediaan air bersih pada prinsipnya harus direncanakan dan dibangun sedemikian rupa sehingga dalam 
pembangunannya dapat memenuhi tujuan antara lain: tersedianya air dalam jumlah yang cukup dengan kualitas yang memenuhi persyaratan air minum, tersedianya air sepanjang waktu atau secara berkesinambungan, dan tersedianya air dengan harga terjangkau oleh masyarakat sebagai konsumen. Lingkungan dengan kepadatan seperti yang terjadi di kota Banda Aceh akan mengurangi kemudahan akses air bersih karena masyarakat yang sebelumnya dapat memperoleh air bersih dari sumur gali menjadi kesulitan akibat terbatasnya lahan dan air tanah nya kuning dan asin akibat peristiwa tsunami 2004. Salah satu cara untuk memperoleh air bersih adalah dengan memanfaatkan pelayanan pemerintah. Perusahaan Daerah Air Minum (PDAM) merupakan suatu badan usaha milik pemerintah daerah yang mengolah dan melayani kebutuhan air bersih masyarakat. Salah satu permasalahan yang telah dan akan timbul dalam pengelolaan air bersih adalah kemampuan PDAM sebagai penyedia air bersih pada umumnya masih terbatas pada pendistribusian air bersih baik kuantitas, kualitas atau kontinuitas.

PDAM Tirta Daroy Kota Banda Aceh saat ini melayani empat cabang yaitu cabang Teuku Umar (TU), cabang Sultan Iskandar Muda (SIM), cabang Teuku Nyak Arief (TNA) dan cabang Syiah Kuala (SK). Penelitian ini hanya terbatas pada Cabang Syiah Kuala dan Teuku Nyak Arief. Penelitian ini bertujuan untuk mengetahui tingkat efektifitas pendistibusian air bersih PDAM Tirta Daroy Kota Banda Aceh pada cabang Syiah Kuala dan cabang Teuku Nyak Arief ditinjau dari aspek pemenuhan terhadap kuantitas, kualitas air dan kontinuitas pengaliran air bersih.

Adapun aspek yang diteliti dalam penelitian ini adalah aspek fisik dari segi kualitas yaitu bau, kekeruhan, dan rasa. Dalam segi kuantitas yaitu tingkat konsumsi rata-rata penduduk per hari dalam satuan liter/orang/hari. Dalam hal kontinuitas adalah waktu pengaliran air dalam satu minggu dalam satuan hari per minggu.

\section{Metode Penelitian}

\section{Lokasi dan Survey Penelitian}

Penelitian pendistribusian air bersih dilakukan di area Banda Aceh yaitu cabang Syiah Kuala dan cabang Teuku Nyak Arief. Pengumpulan data terdiri dari data primer (melalui survey atau observasi langsung di lapangan dengan penyebaran kuisioner kepada responden) dan data sekunder (data yang bersumber dari instansi terkait yaitu PDAM Tirta Daroy Kota Banda Aceh) [2]. Adapun survey yang dilakukan untuk memperoleh data yang dibutuhkan selama penelitian adalah:

\section{a. Survey primer}

Survey primer bertujuan untuk mencari data yang sifatnya tidak tertulis, atapun merupakan data yang memiliki tingkat akurasi yang tinggi [3]. Survei yang dilakukan tersebut adalah:

1) Pengamatan lapangan, tujuannya untuk menghasilkan data-data tidak tertulis yang hanya bisa didapatkan dengan pengamatan secara langsung mengenai kondisi pelayanan distribusi air bersih pada cabang Syiah Kuala dan cabang Teuku Nyak Arief. Kegiatan yang dilakukan dapat berupa pengamatan debit, kontinuitas, dan melihat kondisi fisik air bersih yang dialirkan ke pelanggan pada beberapa sampel rumah.

2) Pembuatan dan pengisian kuesioner dilakukan berdasarkan hasil survei awal, di mana dalam penyusunan pertanyaan dititikberatkan pada tiga variabel yaitu kualitas, kuantitas dan kontinuitas pengaliran pada distribusi air minum. Pertanyaan yang ditulis dalam kuisioner perlu diperhatikan untuk mengantisipasi terjadinya penafsiran ganda terhadap pertanyaan tersebut, agar nantinya jawaban yang diberikan oleh responden dapat dipercaya kebenarannya, sehingga dalam analisis data tidak terdapat keraguraguan di dalamnya yang sangat 
bermanfaat bagi keberhasilan suatu penelitian.

b. Survey sekunder

Survey sekunder merupakan kegiatan pencarian data melalui kajian literatur, hasil penelitian terdahulu, peta-peta yang dibutuhkan, data kependudukan, kondisi wilayah penelitian, ataupun data tertulis lainnya, yang didapatkan langsung dari instansi yang terkait [4]. Tujuan dari survey ini adalah untuk mendapatkan data-data instansional yang selanjutnya diolah dengan alat analisis yang telah tersedia.

\section{Persyaratan dalam Penyediaan Air Bersih}

Air bersih yang digunakan untuk kebutuhan domestik maupun non domestik harus memenuhi persyaratan dari segi kualitas, kuantitas, kontinuitas, maupun tekanan air [5]. Kebutuhan air domestik adalah kebutuhan air bersih yang dimanfaatkan untuk kebutuhan sehari-hari yaitu di dalam rumah tangga. Kebutuhan non domestik adalah kebutuhan air bersih yang dimanfaatkan untuk rumah sakit, perkantoran, sekolah, dan lain-lain. Jumlah penggunaan air untuk kebutuhan non domestik adalah sebesar $20 \%$ dari total kebutuhan domestik [6]. Adapun persyaratan air bersih yang dimaksud sebagai berikut:

\section{Persyaratan Kualitas Air Bersih}

Air bersih adalah air yang digunakan untuk keperluan sehari-hari yang kualitasnya memenuhi syarat kesehatan dan dapat diminum bila dimasak. Syarat- syarat air minum adalah: tidak berwarna, tidak berbau, dan tidak berasa. Air minum juga seharusnya tidak mengandung kuman patogen yang dapat membahayakan kesehatan manusia dan tidak mengandung zat kimia yang dapat mengubah fungsi tubuh, tidak dapat diterima secara estetis, dan dapat merugikan secara ekonomis.

\section{Persyaratan Kuantitas (Debit)}

Kuantitas air bersih sangat erat kaitannya dengan banyak atau sedikitnya jumlah air yang tersedia. Air yang tersedia tersebut dimanfaatkan untuk keperluan penduduk setempat. Persyaratan kuantitas air bersih dapat dilihat dari debit air bersih yang diterima oleh konsumen, di mana debit tersebut sesuai dengan kebutuhan air bersih yang diperlukan. Konsumsi air bersih yang dimanfaatkan oleh konsumen bervariasi, menurut letak kondisi daerah, kebudayaan, dan sektor perekonomian. Jumlah konsumsi air dibedakan menurut kategori kota tempat tinggal seperti diperlihatkan pada Tabel 1.

Tabel 1. Konsumsi Air Dibedakan Menurut Kategori Kota

\begin{tabular}{|c|c|c|c|}
\hline No. & $\begin{array}{c}\text { Kategori } \\
\text { Kota }\end{array}$ & $\begin{array}{c}\text { Jumlah } \\
\text { Penduduk } \\
\text { (orang) }\end{array}$ & $\begin{array}{c}\text { Konsumsi } \\
\text { Air } \\
\text { (lt/org/hari) }\end{array}$ \\
\hline 1 & Metropolitan & $>1.000 .000$ & 210 \\
\hline 2 & Besar & $\begin{array}{c}500.000- \\
1.000 .000\end{array}$ & 170 \\
\hline 3 & Sedang & $\begin{array}{c}100.000- \\
500.000\end{array}$ & 150 \\
\hline 4 & Kecil & $\begin{array}{c}20.000- \\
100.000\end{array}$ & 90 \\
\hline
\end{tabular}

Sumber: Ref

\section{Persyaratan Kontinuitas}

Kontinuitas air bersih adalah air yang dimanfaatkan oleh penduduk terjamin kebutuhannya selama 24 jam tanpa ada kendala dalam perolehan air bersih tersebut. Namun kontinuitas air bersih tidak dapat dijadikan suatu jaminan bahwa aliran air $100 \%$ lancar pada beberapa daerah di Indonesia. Oleh karena itu, perlu adanya ketentuan mengenai pemakaian air yaitu minimal 12 jam per hari yang diterapkan pada saat aktivitas kehidupan padat yaitu mulai dari pukul 06.00 - 18.00 WIB. PDAM menyatakan bahwa distribusi aliran air yang baik adalah jika terpenuhi waktu pengaliran minimal 8 jam sehari.

\section{Persyaratan Tekanan Air}

Cepat atau lambatnya jumlah air yang dialirkan kepada konsumen sangat erat kaitannya dengan kecepatan aliran air. Kecepatan aliran air tersebut harus direncanakan dengan tepat agar air tersebut 
dapat menjangkau seluruh area pelayanan. Pipa transmisi dan pipa distribusi dirancang sedemikian rupa untuk mengalirkan air dari induk ke konsumen dengan tekanan air minimum sebesar 1 atm. Tekanan tersebut harus dijaga supaya dapat merata ke semua pipa distribusi dan tekanan yang dirancang tidak boleh terlalu tinggi dengan tujuan untuk menghindari pecahnya pipa. Tekanan yang rendah dapat menyebabkan kontaminasi air dalam pipa distribusi

\section{Sistem Distribusi Air Bersih}

Sistem distribusi bertujuan untuk mengalirkan air yang telah memenuhi persyaratan baku mutu air ke konsumen. Ada 2 (dua) hal yang harus diperhatikan dalam sistem distribusi adalah: jumlah air minimum yang mengalir kepada pelanngan sesuai dengan kebutuhan yang direncanakan dan air dapat mengalir dengan lancer selama 24 jam

\section{Konsumsi Air Bersih}

Faktor-faktor yang mempengaruhi konsumsi air bersih, yaitu: biaya yang dikeluarkan untuk pemakaian air, pendapatan, suhu atau temperatur, jumlah penduduk, dan komposisi rumah tangga. Secara umum, faktor dominan yang mempengaruhi konsumsi air bersih adalah komposisi rumah tangga. Adapun faktor yang mempengaruhi konsumsi air bersih rumah tangga adalah harga air, penghasilan, jumlah kepala keluarga, jumlah konsumen, cuaca, dan temperatur.

\section{Pengukuran Kualitas Jasa Pelayanan dalam Penyediaan Air Minum}

Kualitas jasa pelayanan air terhadap konsumen atau pelanggan baik yang domestik maupun non domestik diukur dengan menggunakan "Skala Likert". Skala tersebut menunjukkan penilaian konsumen terhadap pelayanan PDAM dalam menyediakan air bersih. Skala tersebut dinyatakan dalam skor $1-5$ yaitu dari sangat tidak puas sampai dengan sangat puas. Adapun Skala Likert tersebut diperlihatkan pada Tabel 2 berikut:
Tabel 2. Skor Penilaian Kepuasan

Konsumen terhadap PDAM

\begin{tabular}{|c|c|c|}
\hline No. & Nilai & Keterangan \\
\hline 1 & 5 & Sangat puas / baik \\
\hline 2 & 4 & Puas/ baik \\
\hline 3 & 3 & Kurang puas / Netral \\
\hline 4 & 2 & Tidak puas / jelek \\
\hline 5 & 1 & $\begin{array}{c}\text { Sangat tidak puas / sangat } \\
\text { jelek }\end{array}$ \\
\hline
\end{tabular}

\section{Kehilangan Air}

Secara umum, kehilangan air disebabkan oleh adanya kebocoran pipa dan kesalahan petugas dalam pembacaan meter. Ada 2 (dua) faktor penyebab kehilangan air pada sistem distribusi air bersih, yaitu sebagai berikut:

1. Kebocoran fisik / teknis yang disebabkan oleh kebocoran pipa, sambungan pipa yang bocor, reservoir yang melimpas keluar, dan pelayanan air minum tanpa meteran.

2. Kebocoran administrasi terutama disebabkan karena meteran air tanpa registrasi, juga termasuk kesalahan dalam sistem pembacaan, pengumpulan dan pembuatan rekening begitu juga kasus-kasus (kolusi, korupsi dan nepotisme) yang berpengaruh baik secara langsung maupun secara tidak langsung terhadap kehilangan air.

Kehilangan air adalah perbedaan antara volume air yang didistribusikan dengan volume air yang tercatat pada pelanggan. Direktorat Jenderal Cipta Karya menetapkan angka kehilangan air sebesar 15-30 \%. Penentuan kehilangan air akibat kebocoran pipa dan kesalahan teknis dari petugas pada saat pembacaan meter dapat ditaksir sampai dengan $20 \%$ dari kebutuhan domestik dan non domestik. Persentase kehilangan air didapatkan dengan mengetahui perbedaan jumlah volume air yang dialirkan dan yang tercatat di meter. Kehilangan air dapat dihitung dengan menggunakan persamaan (1) berikut:

$\mathrm{KA}=\frac{V d-V c}{V d} \quad \mathrm{x} \quad 100 \quad \%$


Di mana:

$\mathrm{KA}=$ Kehilangan air $(\%)$

$\mathrm{Vd}=$ Jumlah volume air yang didstribusikan (liter, $\mathrm{m}^{3}$ )

$\mathrm{Vc}=$ Jumlah volume air yang tercatat pada pelanggan (liter, $\mathrm{m}^{3}$ )

\section{Metode dan Pengolahan Data}

Pada penelitian ini, untuk mendapatkan data tentang efektifitas pendistribusian air bersih PDAM Tirta Daroy Kota Banda Aceh pada cabang Syiah Kuala dan cabang Teuku Nyak Arief, digunakan angket atau kuesioner. Data penelitian ini dianalisis dengan teknik deskriptif kuantatif yang dilengkapi dengan tabel.

Analisis kuantitaif yang dimaksud adalah untuk memberikan gambaran mengenai jumlah air yang digunakan oleh penduduk atau konsumen PDAM Tirta Daroy Kota Banda Aceh pada cabang Syiah Kuala dan cabang Teuku Nyak Arief sesuai dengan yang disyaratkan dalam kualitas, kuantitas, dan kontinuitas air bersih.

Penelitian yang dilaksanakan dengan menggunakan teknik deskriptif kuantitaif yaitu penyebaran kuisioner kepada konsumen. Penelitian ini menggunakan sampel yang mewakili konsumen yang tersebar dari cabang Syiah Kuala dan cabang Teuku Nyak Arief. Hal ini dikarenakan penelitian dengan menggunakan jumlah populasi secara keseluruhan akan memakan waktu yang lama dan biaya yang sangat besar.

Sampel didefinisikan sebagai bagian dari jumlah dan ciri-ciri atau sifat-sifat yang terdapat pada suatu populasi. Sampel yang diambil secara acak dapat mewakili jumlah populasi yang ada. Populasi adalah penjumlahan total dari keseluruhan obyek yang diteliti. Adapun sampel yang digunakan dalam penelitian ini dapat dihitung dengan menggunakan persamaan (2) sebagai berikut:
$n=\frac{N}{\left(N e^{2}\right)+1}$

(2)

Di mana:

$\mathrm{n}$ = Ukuran sampel

$\mathrm{N}=$ Ukuran populasi

$\mathrm{E}=$ Nilai kritis (batas ketelitian, secara umum digunakan $10 \%$ )

\section{Hasil Dan Pembahasan}

Penelitian dengan menggunakan metode kuantitatif yaitu menyebarkan 392 exemplar kuesioner kepada pelanggan PDAM Tirta Daroy Kota Banda Aceh pada cabang Syiah kuala (SK) dan cabang Teuku Nyak Arief (TNA). Kuesioner ini terdiri dari karakteristik pelanggan, parameter kuantitas, parameter kontinuitas dan parameter kualitas terhadap efektifitas pendistribusian air bersih PDAM Tirta Daroy.

\section{Jumlah Pelanggan dan Pemakaian Air}

Sumber air bersih yang digunakan masyarakat pada cabang Syiah kuala (SK) dan cabang Teuku Nyak Arief (TNA) berasal dari distribusi PDAM dan sebagiannya lagi menggunakan air sumur. Adapun jumlah pelanggan di cabang SK sebanyak 10.638 orang dengan jumlah pemakaian air sampai dengan bulan Desember 2017 adalah $286.396 \mathrm{~m}^{3}$. Untuk pelanggan di cabang TNA sebanyak 9.915 orang dengan jumlah pemakaian air sampai dengan bulan Desember 2017 adalah $274.893 \mathrm{~m}^{3}$. Sehingga pemakaian air untuk cabang SK dan TNA adalah sebesar 561.289 $\mathrm{m}^{3}$.

\section{Instalasi Pengolahan Air Minum}

PDAM Tirta Daroy Kota Banda Aceh mempunyai 2 instalasi pengolahan air dengan daerah pelayanan sebanyak 4 cabang. Instalasi Pengolahan Air Perusahaan Daerah Air Minum Tirta Daroy Kota Banda Aceh terdiri dari 2 instalasi pengolahan air dengan panjang pipa transmisi dan distribusi yang terpasang 
adalah $500.000 \mathrm{~m}$. Adapun jenis pipa yang digunakan khususnya untuk mendistribusi air bersih dari Instalasi Pengolahan Air Lubok Batee dan Instalasi Pengolahan Air Siron adalah pipa jenis GIP, HDPE, ACP, PVC. Instalasi produksi air Lubok Batee dan Siron terhadap air yang didistribusikan dapat dilihat pada Tabel 3.

Tabel 3. Instalasi Produksi dan Distribusi air

\begin{tabular}{|l|c|c|}
\hline \multirow{2}{*}{ Instalasi } & \multicolumn{2}{|c|}{ Produksi } \\
\cline { 2 - 3 } & $\mathbf{m}^{3}$ & Liter/detik \\
\hline IPA Siron & 142.560 & 142.560 .000 \\
\hline $\begin{array}{l}\text { IPA Lubok } \\
\text { Batee }\end{array}$ & 622.080 & 622.080 .000 \\
\hline Jumlah & 764.640 & 764.640 .000 \\
\hline
\end{tabular}

Sumber: Ref

Kehilangan air pada sistem produksi IPA Lubok Batee dan Siron

Adapun besarnya kehilangan air untuk IPA Lubok Batee dan IPA Siron PDAM Tirta Daroy Kota Banda Aceh yaitu:

$$
\begin{gathered}
K A=\frac{V_{d}-V_{c}}{V_{d}} \times 100 \% \\
K A=\frac{764,640-561,289}{764,640} \times 100 \% \\
K A=26,59 \%
\end{gathered}
$$

Angka kehilangan air yang diijinkan di Indonesia adalah maksimal 20\% untuk instalasi lama. Hal ini menunujukkan bahwa pada IPA Lubok Batee dan IPA Siron tingkat kehilangan air di kategorikan kurang baik karena kehilangan air mencapai 26,59 $\%$.

\section{Sampel}

Jumlah sampel dari populasi pelanggan cabang SK dan TNA dihitung dengan menggunakan persamaan sebagai berikut:
Sampel Pelanggan air bersih pada cabang Syiah Kuala dan Teuku Nyak Arief:

Jumlah pelanggan cabang $\mathrm{SK}=10.638$ sambungan

Jumlah pelanggan cabang TNA= sambungan

Total $=20.553$ sambungan

Jumlah sampel sebagai berikut:

$$
\begin{gathered}
n=\frac{20.553}{\left\lfloor 20.553\left(0,05^{2}\right)\right\rfloor+1} \\
n=\frac{20.553}{52,3825} \\
n=392,368 \\
n=392 \text { sampel }
\end{gathered}
$$

Pengambilan sampel dilakukan dengan cara sampel non probabilitas atau pengambilan sampel berdasarkan pertimbangan dalam klasifikasi sampel purposive. Dimana hanya kepala keluarga yang berlangganan PDAM saja yang dipertimbangkan sebagai sampel. Selanjutnya terpilih Tiap-tiap zona diambil secara proporsional dari populasi cabang. Populasi pelanggan terdistribusi pada kedua cabang masing-masing. Dari persentase ini didapatkan jumlah responden pada setiap cabang. Rinciannya dapat dilihat pada Tabel 4. Berikut:

Tabel 4. Rincian Responden Berdasarkan Cabang

\begin{tabular}{|r|c|c|c|}
\hline No & Cabang & Jumlah Sampel & Presentase (\%) \\
\hline $\mathbf{1}$ & SK & 203 & 51,8 \\
\hline $\mathbf{2}$ & TNA & 189 & 48,2 \\
\hline \multicolumn{2}{|c|}{ Total } & $\mathbf{3 9 2}$ & $\mathbf{1 0 0}$ \\
\hline
\end{tabular}

\section{Kuantitas Pengaliran Air}

Jawaban pelanggan PDAM cabang Syiah Kuala dan cabang Teuku Nyak Arief terhadap kuantitas air yang disalurkan oleh pihak PDAM kepada pelanggan menyatakan setuju dengan nilai rata-rata 3,71 seperti diperlihatlkan pada Tabel 5. 
Tabel 5. Kuantitas Pendistribusian Air

\begin{tabular}{|c|c|c|c|c|c|c|c|c|c|c|c|c|}
\hline \multirow[t]{2}{*}{ No } & \multirow[t]{2}{*}{ Atribut Pertanyaan } & \multicolumn{2}{|c|}{$\begin{array}{l}\text { Sangat } \\
\text { Tidak } \\
\text { Puas }\end{array}$} & \multicolumn{2}{|c|}{$\begin{array}{l}\text { Tidak } \\
\text { Puas }\end{array}$} & \multicolumn{2}{|c|}{$\begin{array}{c}\text { Kurang } \\
\text { Puas }\end{array}$} & \multicolumn{2}{|c|}{ Puas } & \multicolumn{2}{|c|}{$\begin{array}{l}\text { Sangat } \\
\text { Puas }\end{array}$} & \multirow{2}{*}{$\begin{array}{l}\text { Rata } \\
\text {-rata } \\
\%\end{array}$} \\
\hline & & Fr & $\%$ & $\mathrm{Fr}$ & $\%$ & $\mathrm{Fr}$ & $\%$ & Fr & $\%$ & $\mathrm{Fr}$ & $\%$ & \\
\hline 1 & $\begin{array}{l}\text { Apakah } \\
\text { jumlah volume air } \\
\text { bersih dari PDAM } \\
\text { dapat memenuhi } \\
\text { kebutuhan air bersih di } \\
\text { rumah anda }\end{array}$ & 0 & 0,0 & 0 & 0,0 & 43 & 11,0 & 283 & 72,2 & 66 & 16,8 & 4,06 \\
\hline 2 & $\begin{array}{l}\text { Untukmememnuhi } \\
\text { kebutuhan air bersih } \\
\text { anda sekeluarga sehari- } \\
\text { hari, apakah } \\
\text { masih pernah } \\
\text { menggunakan air bersih } \\
\text { selain dari PDAM } \\
\text { (misalnya : air sumur, air } \\
\text { sungai, dll) }\end{array}$ & 0 & 0,0 & 852 & 1,7 & 85 & 21,7 & 204 & 52,0 & 18 & 4,6 & 3,40 \\
\hline 3 & $\begin{array}{l}\text { Apakah air PDAM } \\
\text { mengalir rumah anda } \\
\text { dengan lancer tanpa } \\
\text { menggunakan bantuan } \\
\text { pompa air }\end{array}$ & 0 & 0,0 & 0 & 0,0 & 255 & 65,1 & 127 & 32,4 & 10 & 2,6 & 3,38 \\
\hline 4 & $\begin{array}{l}\text { Jika air PDAM kurang } \\
\text { lancar apakah anda } \\
\text { menggunkan pompa air } \\
\text { untukmenariknya }\end{array}$ & 0 & 0,0 & 0 & 0,0 & 69 & 17,6 & 293 & 74,7 & 30 & 7,7 & 3,90 \\
\hline 5 & $\begin{array}{l}\text { Apakah rata-rata } \\
\text { pemakain air bersih } \\
\text { PDAM perbulan anda } \\
\text { stabil }\end{array}$ & 0 & 0,0 & 0 & 0,0 & 78 & 19,9 & 288 & 73,5 & 26 & 6,6 & 3,87 \\
\hline & Rata - rata (\%) & & & & & & & & & & & 3,71 \\
\hline
\end{tabular}

Sumber: Penulis

Dari segi kuantitas, PDAM mampu memberikan distribusi air yang memadai untuk kebutuhan sehari-hari terhadap pelanggan. Dimana responden memberikan jawaban puas dengan tingkat nilai rata-rata $3,71 \%$ dari beberapa item pertayaan yang telah diberikan.

\section{Kontinuitas Pengaliran Air}

Jawaban konsumen tentang jadwal pengaliran air yang dilakukan oleh PDAM bedasarkan jumlah responden 392 menyatakan setuju dengan nilai rata-rata 3,99 yang dapat dilihat pada Tabel 6 .

Tabel 6. Jadwal Kontinuitas Pendistribusian Air

Dari segi kuantitas, PDAM mampu memberikan distribusi air yang memadai untuk kebutuhan sehari-hari terhadap pelanggan. Dimana responden memberikan jawaban puas dengan tingkat nilai rata-rata $3,71 \%$ dari beberapa item pertayaan yang telah diberikan.

\section{Kontinuitas Pengaliran Air}

Jawaban konsumen tentang jadwal pengaliran air yang dilakukan oleh PDAM bedasarkan jumlah responden 392 menyatakan setuju dengan nilai rata-rata 3,99 yang dapat dilihat pada Tabel 6 .
Tabel 6. Jadwal Kontinuitas Pendistribusian Air

\begin{tabular}{|c|c|c|c|c|c|c|c|c|c|c|c|c|}
\hline \multirow[t]{2}{*}{ No } & \multirow[t]{2}{*}{ Atribut Pertanyaan } & \multicolumn{2}{|c|}{\begin{tabular}{|l} 
Sangat \\
Tidak \\
Puas
\end{tabular}} & \multicolumn{2}{|c|}{$\begin{array}{l}\text { Tidak } \\
\text { Puas }\end{array}$} & \multicolumn{2}{|c|}{$\begin{array}{l}\text { Kurang } \\
\text { Puas }\end{array}$} & \multicolumn{2}{|c|}{ Puas } & \multicolumn{2}{|c|}{$\begin{array}{l}\text { Sangat } \\
\text { puas }\end{array}$} & \multirow{2}{*}{$\begin{array}{c}\begin{array}{c}\text { Rata- } \\
\text { rata }\end{array} \\
\%\end{array}$} \\
\hline & & $\mathbf{F r}$ & $\%$ & $\mathbf{F r}$ & $\%$ & $\mathbf{F r}$ & $\%$ & $\mathrm{Fr}$ & $\%$ & $\mathbf{F r}$ & $\%$ & \\
\hline 1 & $\begin{array}{l}\text { Apakah dalam satu } \\
\text { minggu anda setiap hari } \\
\text { memperoleh air bersih } \\
\text { dari PDAM }\end{array}$ & 0 & 0,0 & 1 & 0,3 & 51 & 13,0 & 248 & 63,3 & 92 & 23,5 & 4,10 \\
\hline 2 & $\begin{array}{l}\text { Apakah rumah anda } \\
\text { selalu mendapatkan air } \\
\text { PDAM selam } 24 \mathrm{jam}\end{array}$ & 0 & 0,0 & 2 & 0,5 & 67 & 17,1 & 272 & 69,4 & 51 & 13,0 & 3,95 \\
\hline 3 & $\begin{array}{l}\text { Pada musim kemarau } \\
\text { apakah selalu terpenuhi } \\
\text { air dari PDAM di } \\
\text { lingkungan anda }\end{array}$ & 0 & 0,0 & 0 & 0,0 & 43 & 11,0 & 296 & 75,5 & 53 & 13,5 & 3,91 \\
\hline 4 & $\begin{array}{l}\text { Apakah anda selalu } \\
\text { terpenuhi air daro PDAM } \\
\text { untuk pemakain sehari- } \\
\text { hari }\end{array}$ & 0 & 0,0 & 0 & 0,0 & 43 & 11,0 & 296 & 75,5 & 53 & 13,5 & 4,03 \\
\hline & Rata - rata (\%) & & & & & & & & & & & 3,99 \\
\hline
\end{tabular}

Sumber: Penulis

Dari segi kontinuitas, PDAM sudah mampu memberi pelayanan 24 jam per hari selama 7 hari dengan penilaian rata-rata dari responden 3,99\%. Dalam hal ini, PDAM sudah mampu memenuhi minimal standar prioritas pemakaian air selama 12 jam per hari selama 7 hari.

\section{Kualitas Pengaliran Air}

Jawaban konsumen tentang kualitas air yang dilakukan oleh PDAM bedasarkan jumlah responden 392 menyatakan setuju dengan nilai rata-rata 3,42 , yang dapat dilihat pada Tabel 7.

Tabel 7. Kualitas Pendistribusian Air

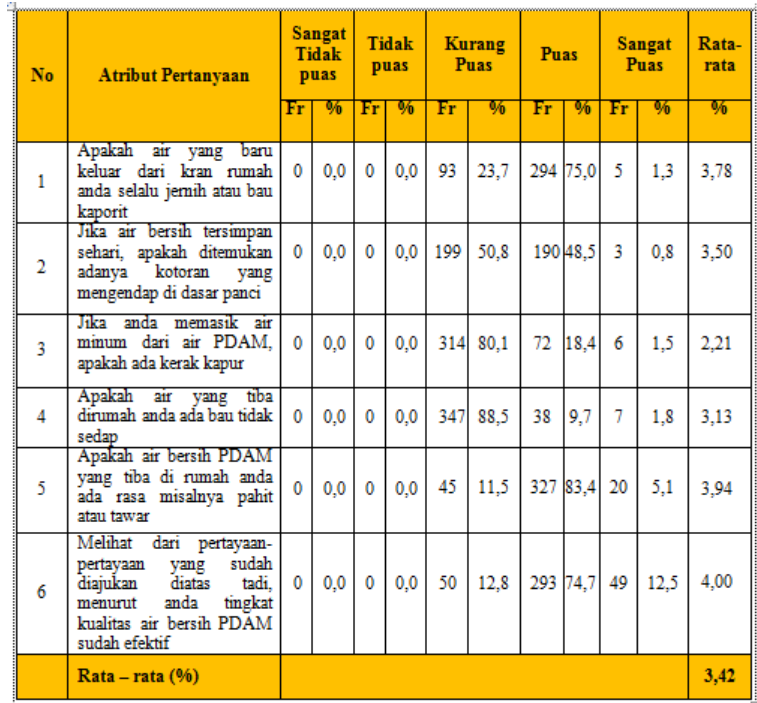

Sumber: Penulis

Dari segi kualitas air, PDAM rata-rata mampu mendistribusikan air yang tidak memiliki bau, tidak memiliki rasa, jernih, dan tidak berwarna dengan penilaian ratarata dari responden $3,42 \%$. Hal tersebut telah memenuhi standar berdasarkan 
Peraturan Menteri Kesehatan RI No. 492/Menkes/Per/IV/2010 tentang

Persyaratan Kualitas Air.

\section{Efektivitas Pendistribusian Air Bersih}

Jumlah Sambungan Rumah (SR) Pada cabang Syiah Kuala dan cabang Teuku Nyak Arief sebanyak 20.553 sambungan. Jumlah sampel sebanyak 392 sampel, di mana rata-rata jumlah anggota keluarga adalah 5-6 orang (sebesar 38,5 \%), lama berlanggan air PDAM adalah 11-15 tahun (sebesar 77,6 \%), dan kapasitas bak penampung air adalah 1,1-2 $\mathrm{m}^{3}$ (sebesar $31,1 \%$ ). Efektivitas pendistribusian air bersih pada cabang Syiah Kuala dan cabang Teuku Nyak Arief dengan tingkat kuantitas sebesar 3,71\%, kontinuitas sebesar 3,99 $\%$, dan kualitas sebesar 3,42\%.

$$
\begin{aligned}
& \text { Efektivitas Air Bersih } \\
& =\frac{\text { Kuantitas }+ \text { Kontinuitas }+ \text { Kualitas }}{3}
\end{aligned}
$$

$$
\begin{aligned}
& \text { Efektivitas Air Bersih } \\
& \quad=\frac{3,71 \%+3,99 \%+3,42 \%}{3} \\
& \text { Efektivitas Air Bersih }=3,71 \%
\end{aligned}
$$

Hasil penliaian efektivitas air bersih rata-rata adalah di atas 3,71\%. Hal ini berarti tingkat efektifitas pendistribusian air bersih PDAM Tirta Daroy Kota Banda Aceh mayoritas menyatakan sudah efektif ditinjau dari segi kualitas, kontinuitas, dan kuantitas.

\section{Kesimpulan}

Berdasarkan hasil penelitian kuantitaif pendistribusian air bersih PDAM Tirta Daroy Kota Banda Aceh pada cabang Syiah Kuala (SK) dan cabang Teuku Nyak Arief (TNA), dapat diambil kesimpulan sebagai berikut:

1. Kuantitas air untuk cabang Syiah kuala dan cabang Teuku Nyak Arief sudah efektif, karena mendapat jawaban setuju dari jumlah 392 responden dengan tingkat nilai rata-rata $3,71 \%$ yang dapat diartikan konsumen merasa puas walaupun harus menggunakan pompa untuk mendapatkan air PDAM.

2. Kontinuitas air yang efektif mengalir secara kontiniu selama 24 jam/hari untuk cabang Syiah Kuala dan cabang Teuku Nyak Arief medapat penilaian setuju dengan tingkat nilai rata-rata 3,99 $\%$ yang telah dijawab oleh pelanggaan.

3. Kualitas air mendapat penilaian yang efektif dari pelanggan dengan bobot nilai rata-rata $3,42 \%$ yang artinya pelanggan menyatakan setuju dengan pelayanan yang telah diberikan oleh pihak PDAM.

4. Berdasarkan persepsi 392 responden pada cabang Syiah Kuala dan cabang Teuku Nyak Arief tentang tingkat efektifitas pendistribusian air bersih PDAM Tirta Daroy Kota Banda Aceh, mayoritas menyatakan sudah efektif ditinjau dari segi kualitas, kontinuitas, dan kuantitas dengan nilai rata-rata 3,71 $\%$.

\section{Saran}

Adapun beberapa saran yang dapat direkomendasikan oleh peneliti untuk memperbaiki kekurangan-kekurangan yang terdapat dalam hasil penelitian yang diteliti sebagai berikut:

1. Dalam upaya meningkatkan kuantitas dan kontinuitas pendistribusian air bersih PDAM, sebaiknya dibangun water tower untuk meningkatkan tekanan pada pipa distribusi agar pelanggan tidak lagi menggunakan pompa. Sehingga pelanggan mendapatkan air secara merata.

2. Dalam upaya meningkatkan pendistribusian air bersih bagi masyarakat, perlu dilakukan perencanaan pengembangan yang berorientasi pada wilayah-wilayah prioritas yang sulit mendapatkan air bersih.

\section{Daftar Pustaka}

P. U. Departemen, "Petunjuk Teknis Perencanaan Rancangan Teknik Sistem Penyediaan Air Minum Perkotaan," DPU Direktorat 
Jenderal Cipta Karya. Jakarta, 1998.

L. Asri and R. P. Setiawan, "Faktor yang Memengaruhi Pelayanan Ditribusi Air Bersih pada Permukiman Perkotaan di Pusat Kegiatan Lokal Kabupaten Sampang.”

M. Kencanawati, M. Mustakim, and M. Ramdhan, "ANALISIS SISTEM DISTRIBUSI AIR BERSIH BERDASARKAN PARAMETER DEBIT DAN TEKANAN AIR," $J$. Ilm. Tek. Sipil TRANSUKMA (Tanah Transp. Strukt. Manaj. Kontruksi), vol. 2, no. 1, pp. 1-6, 2016.

N. Masombe, F. Halim, and A. Binilang, "Perencanaan Sistem Pelayanan Air Bersih Di Kelurahan Bonkawir Kabupaten Raja Ampat Provinsi Papua Barat," J. Sipil Statik, vol. 3, no. $11,2015$.

M. KESEHATAN, "PERATURAN MENTERI KESEHATAN NOMOR 492/MENKES/PER/IV/2010 TENTANG PERSYARATAN KUALITAS AIR MINUM," 2010.

Fitriadi, "Rancangan Strategi Peningkatan Kapasitas Produksi Pada Sistem Distribusi Produksi AIr PDAM Tirta Meulaboh, Kabupaten Aceh Barat," Magister Tek. Ind. Univ. Sumatera Utara, Medan, 2013.

C. S. Silvia, "Analisis KInerja Sistem DIstribusi Jaringan AIr Bersih PDAM Tirta Meulaboh (Studi Kasus Pada Zona Layanan Kecamatan Johan Pahlawan Kabupaten Aceh Barat)," Tesis, Progr. Stud. Tek. Sipil Pascasarj. Unsyiah, 2014.

Depkimpraswil, "Pedoman/ Petunjuk Teknis
Manajemen Air Minum Perkotaan," Jakarta, 2002.

Suhardi, "Kajian Spasial Tingkat Pelayanan Air Bersih di Perumahan Limbangan Baru Kabupaten Banjar Negara," Tesis, Progr. Pasca Sarj. Univ. Diponegoro, Semarang, 2007.

E. Damanhuri, "Pendekatan Sistem Dalam Pengendalian dan Pengoperasian Sistem Jaringan Distribusi Air Minum," Bandung, Jur. Tek. Lingkung. FTSP-ITB, 1989.

M. H. Worthington. C Andrew, "An Empirical Survey of Residential Water Demand Modelling," $J$. Econ. Surv. Vol. 22, No., 2008.

T. H. Joachim Schleich, "Deteminants Of Residential Water Demand in Germany," Work. Pap. Sustain. Innov. No. S 3, 2007.

S. Prof, "Dr. metode penelitian pendidikan pendekatan kuantitatif, kulaitatif dan R \& D." Bandung: Cv. Alfa Beta, 2012.

C. R. Mampuk, T. Mananoma, and L. Tanudjaja, "Pengembangan Sistem Penyediaan Air Bersih di Kecamatan Poso Kota Sulawesi Tengah," J. Sipil Statik, vol. 2, no. $5,2014$.

Nugraha, "Studi Kehilangan Air Akibat Kebocoran Pipa Pada Jalur Distribusi PDAM Kota Magelang (Studi Kasus: Perumahan Armada Estate dan Depkes)," Vol. 7, No. 2, Sept. 2010, ISSN 1907-187X, 2010.

H. A. M. DANI, "PERENCANAAN PIPA DISTRIBUSI AIR BERSIH KELURAHAN SAMBALIUNG KECAMATAN SAMBALIUNG KABUPATEN BERAU," KURVA S J. Mhs., vol. 4, no. 1, pp. 178-186, 
Jurnal Sains Riset (JSR)

$p$-ISSN 2088-0952, $e$-ISSN 2714-531X

2014.

Idris F., "Analisa Kinerja Jaringan Distribusi Air Bersih Di Perumnas Lingke Kecamatan Syiah Kuala Kota Banda Aceh," Magister Tek. Sipil Univ. Syiah Kuala, Banda
Aceh, 2012.

P. T. Daroy, "Peningkatan pelayanan air minum kota Banda Aceh," Banda Aceh, 2016. 